\title{
Comparative Study between Intracorporeal and Extracorporeal Sliding-Knot in Ligation of the Base of the Appendix in Laparoscopic Appendectomy
}

\author{
MOHAMMED H. ARAKEEB, M.Sc.; MAHMOUD M. EL-SHERIF, M.D.; \\ MOHAMMED ABDULLAH HABLUS, M.D.; ABD EL-MONEIM A. NAGY, M.D. and \\ MOHAMMED M. EL-SHEIKH, M.D.
}

The Department of Gastrointestinal, Liver and Laparoscopic Surgery, Faculty of Medicine, Tanta University

\begin{abstract}
Background: Suture ligation of appendix base during laparoscopic appendectomy with Extracorporeal Sliding-Knot (ECK) is associated with better outcomes than Intracorporeal Knot (ICK) continues to be a matter of debate.
\end{abstract}

Aim of the Study: Is to compare Extracorporeal Slidingknot (ECK) and Intracorporeal Knot (ICK) in ligation of the base of the appendix in laparoscopic appendectomy.

Patients and Methods: This prospective randomized comparative study was carried out in Gastrointestinal, Liver \& Laparoscopic Surgery Unit of Tanta University Hospitals from May 2016 till May 2017 on 30 patients with acute appendicitis divided into two equal groups; Group I: Were subjected to extracorporeal sliding-knot (15 cases) and Group II: Were subjected to intracorporeal knot (15 cases).

Results: The mean age of ECK group was $29 \pm 5.10$ years, compared to $29.33 \pm 5.39$ in ICK group. There were 9 males and 6 females in ECK group, compared to 7 males and 8 females in ICK group. A highly statistically significant difference was present in operative time between both groups; ECK Group had operative time mean of $46.07 \pm 11.70$ minutes, compared to $61.73 \pm 11.33$ minutes in ICK group. Superficial wound infection developed in one patient in ECK group and two patients in ICK group. Only one patient in ICK group developed post-operative abscess in the RIF.

Conclusion: ECK technique had significant shorter operative time in comparison with ICK that needs more laparoscopic skills. Incidence of post-operative wound infection, intraabdominal abscess were higher in ICK technique, but these findings were not statistically significant.

Key Words: ECK - ICK - Intraoperative complications Post-operative complications - Laparoscopic appendectomy.

Correspondence to: Dr. Mohammed H. Arakeeb, The Department of Gastrointestinal, Liver and Laparoscopic Surgery, Faculty of Medicine, Tanta University

\section{Introduction}

LAPAROSCOPIC Appendectomy (LA) is currently a well-established and widely accepted method. It has a lot of advantages as compared with open approach technique, including less pain in the post-operative period, faster return to normal activity and work, shorter hospital stay and lower percentage of wound infections $[\mathbf{1 , 2}]$.

Adequate closure of the appendix stump is very important to avoid serious complications such as post-operative fistula, peritonitis, and sepsis. During LA, several modifications with new materials have been introduced for optimizing and controlling the appendiceal stump closure including; staplers, endoloop, titanium clips, nonabsorbable polymer clips (Hem-o-lock clips), hand-made loops, suture closure through extracorporeal sliding-knot or intracorporeal knot ligation [3].

Tying the knots intra-abdominally with the help of laparoscope is challenging and difficult due to limited space for movement, lack of twist movement at the wrist joint, the fulcrum for movement due to long instruments, is far from the desired site and it also requires great manual dexterity [4]

Extracorporeal knotting is an alternative technique which is widely used. To make use of extracorporeal sliding-knots, the idea is to make the knot outside the body and then slide it in to do the job. The knot applied must be as secure as the traditional ones, quick and easy to apply [4].

The most common extracorporeal sliding-knots are; Roeder's knot, Mishra's knot, Gea extracorporeal knot, Duncan loop, Tayside knot, Tennessee slider, Nicky's knot, SMC knot, Weston knot, and 
Meltzer's knot [5,6]. The most common intracorporeal knot tying techniques are; intracorporeal Square Knot (Loop Method, Wind Method \& Tumble Square Knot), Surgeons Knot, Tying laparoscopic intracorporeal knots with one instrument: Dowais tie and Single instrument intracorporeal knot tying (Magid Ismail, Rafik Shalaby technique) $[7,8]$

\section{Patients and Methods}

This study is a prospective randomized comparative study included 30 patients, admitted to Gastrointestinal, Liver \& Laparoscopic Surgery Unit of Tanta University Hospitals, El-Gharbeia, Egypt that were diagnosed as appendicitis and were subjected to laparoscopic appendectomy starting from May 2016 till May 2017. The thirty patients were divided into 2 equal groups; Group I were subjected to extracorporeal sliding-knot ligation (15 cases) and Group II were subjected to intracorporeal knot (15 cases).

All cases that diagnosed as clinically evident appendicitis pre-operatively were included in our study except; patient under 18 years of age, perforated appendicitis with peritonitis, pre-operatively diagnosed appendicular mass or abscess, severely septic patients for whom a laparotomy is indicated, patients with severe lung or cardiac diseases, and pregnancy (1 st and 3 rd trimester).

All patients were subjected to; history taking with emphasis on; onset, course and duration of pain, clinical examination with emphasis on; pulse, temperature, maximum point of tenderness and cough tenderness, right iliac fossa rebound tenderness, guard, rigidity or palpation of a mass, Rovsing's sign, psoas sign and obturator internus sign. Also investigations were done in form of: Total leucocytic count, C-reactive protein, urine analysis, pregnancy test in females and imaging studies in form of; pelviabdominal ultrasound and plain Xray of the abdomen and pelvis in erect position.

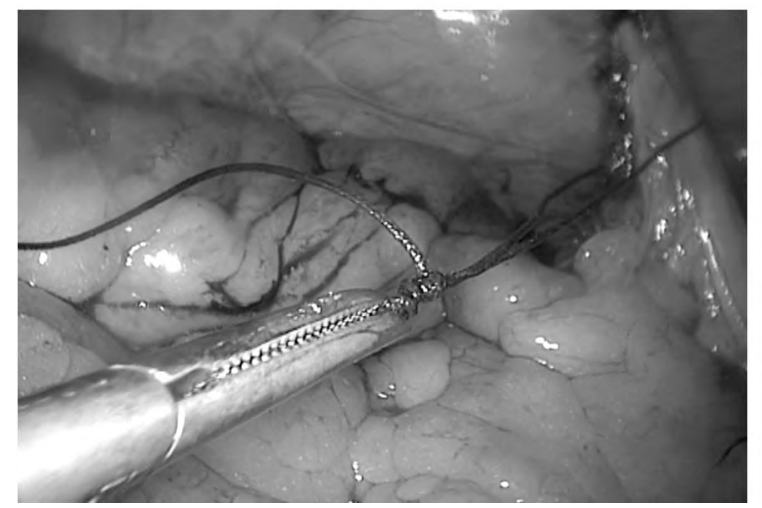

Fig. (1): Tightening the ECK with Maryland around the base.

\section{Surgical technique:}

Creation of pneumoperitoneum was done by either closed or open techniques through supraumbilical incision. We used carbon dioxide for insufflation with a range pressure of $12-14 \mathrm{mmHg}$, when pneumoperitoneum is established, the $30^{\circ} 10 \mathrm{~mm}$ telescope is inserted inside the umbilical port.

We utilized a three-port technique, with one umbilical $10 \mathrm{~mm}$ port for the camera and the first $5 \mathrm{~mm}$ working port at midline $4-5 \mathrm{~cm}$ above the pubis under laparoscopic vision with care to avoid injury of the bladder, the second $5 \mathrm{~mm}$ working port is at left iliac fossa medial to left anterior superior iliac spine.

Firstly identification of the appendix in the right iliac fossa was done and confirmation of the diagnosis, then mobilization and holding the appendix with atraumatic grasper with traction towards anterior abdominal wall, any adhesions between the appendix and the surrounding structures were lysed with a combination of blunt and sharp dissection.

The mesoappendix is then cauterized using unipolar diathermy starting from the tip of the appendix to its base combining the coagulation and cutting electrocautery. It is worth mentioning that a harmonic scalpel was used in few cases for the same purpose.

ECK technique: There are various methods of ECK, in our study we used Roeder's and Mishra sliding knot with vicryl-0-suture. Three knots were used for ligation of the base of the appendix. The Roeder's knot was prepared outside the abdominal cavity through formula of (1:3:1), one hitch, three winds and one locking hitch then the knot was checked for sliding. Knot was held to abdominal cavity through the trocar. Once inside the abdominal cavity, the appendix was placed through the loop. The knot was tightened with a Maryland. End of the knot was trimmed with scissors.

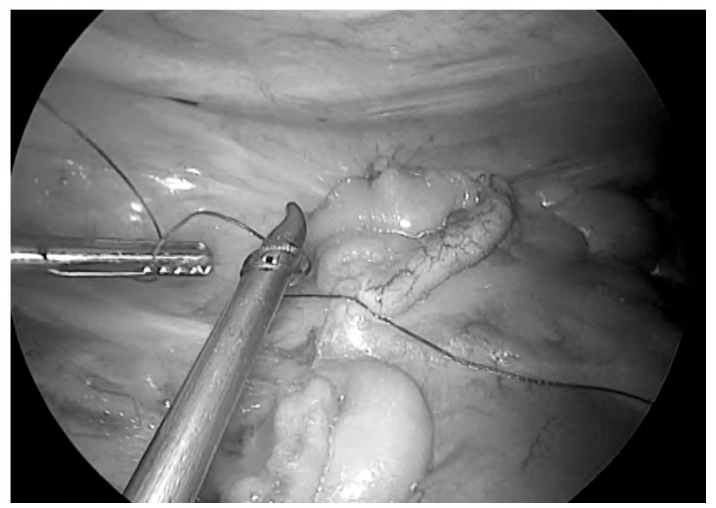

Fig. (2): Suturing the first intracorporeal knot around the base. 
ICK technique: Intracorporeal knot was done with $20 \mathrm{~cm}$ of vicryl-0-suture. Three knots were used around the appendix base using square knot and surgeons knot.

Lastly the specimen was removed through the port with the valve held open. Peritoneal lavage was done and drain insertion (if needed), caecum and stump were visualized using the camera, for checking hemostasis and security. After resection of the appendix, histopathological study was ordered for all specimens.

\section{Results}

Total number of patients in our study was 30 patients that were divided into two equal groups; Group I: ECK group (15 patients) and Group II: ICK group (15 patients).

- The demographic characteristics of our study groups: The mean age of ECK group was $29 \pm 5.10$ years, compared to $29.33 \pm 5.39$ in ICK group. There were 9 males $(60 \%)$ and 6 females $(40 \%)$ in ECK group, while there were 7 males $(46.7 \%)$ and 8 females $(53.3 \%)$ in ICK group. Among the female patients there were 2 pregnant cases; one in each group in the 18 th and 20th gestational week respectively. The mean BMI of ECK group was $25.45 \pm$ $2.76 \mathrm{~kg} / \mathrm{m}^{2}$ compared to $26.68 \pm 2.94 \mathrm{~kg} / \mathrm{m}^{2}$ in ICK group, no statistically significant difference was found as regard age, gender and BMI between both study groups.

- Laboratory investigation characteristics: No statistically significant difference in leucocytic count and CRP between both groups. ECK group had leucocytic count mean of $8310.20 \pm 6786.06$, compared to $8966.73 \pm 4092.62$ in ICK group. Regarding CRP level; in ECK group the mean of CRP level was 9.47 while in ICK group the mean of CRP was 15 .

- Alvarado score: The mean of Alvarado score in ECK group was 6.87 \pm 1.68 , while in ICK group the mean of Alvarado score was $7.33 \pm 1.63$ with $p$-value $=0.448$ which is statistically insignificant.

- Operative data: Creation of pneumoperitoneum was accomplished through open technique in one patient $(6.7 \%)$ in each group while in the other 14 patients $(93.3 \%)$ we used closed method technique. Regarding drain insertion; in ECK group we inserted a tube drain in 4 patients (26.7\%), while in ICK group we inserted a drain in 2 patients $(13.3 \%)$, with statistically insignificant difference between both groups. A highly statistically significant difference was present in operative time between both groups. ECK group had a shorter operative time than ICK group. Operative time was $46.07 \pm 11.70$ minutes in ECK group compared to $61.73 \pm 11.33$ minutes in ICK group with $p$-value $=0.001$.

During our study, we did not convert to the open procedure in any case additionally there was no significant intraoperative bleeding in both groups.

- Type of the appendix: In ECK group; simple appendicitis was found in 10 patients $(66.66 \%)$, complicated appendicitis in 3 patients $(20 \%)$, and no macroscopic signs of inflammation in 2 patients $(13.33 \%)$. On the other hand, in ICK group; simple appendicitis was found in 8 patients $(53.33 \%)$, complicated appendicitis in 5 patients $(33.33 \%)$, and no macroscopic signs of inflammation in 2 patients $(13.33 \%)$. In case of macroscopic noninflamed appendix while no other obvious abdominal pathology was detected explaining right-lower quadrant pain, we were still keen to remove the appendix. Histological examination showed acute appendicitis in $28(93.33 \%)$ out of 30 patients. There was no statistically significant difference between two groups as regards the type of appendicitis $(p=0.697)$.

- Post-operative return of intestinal sounds \& starting feeding: The intestinal sound returned with starting the oral feeding in ECK group after $14.40 \pm 4.97$ hours post-operatively, while in ICK group intestinal sounds returned after $17.60 \pm 6.20$ hours, with $p$-value $=0.130$ which is statistically insignificant.

- Post-operative complications: Superficial wound infection developed in one patient $(6.7 \%)$ in ECK group and two patients (13.3\%) in ICK group, also each group had only one patient (6.7\%) with post-operative delayed peristalsis, but regarding intraabdominal abscess there was one patient only in ICK group who developed post-operative abscess in the RIF. Additionally there was no patient developed fecal fistula, bleeding or port site hernia. No statistical significant difference between two groups in post-operative complications.

- Duration of hospital stay in days among the study groups: 4 cases (26.7\%) in ECK group were discharged in ${ }^{1 \text { st }}$ post-operative day in comparison to 2 cases $(13.3 \%)$ in ICK group. 11 cases $(73.3 \%)$ were discharged in 2 nd post-operative day in ECK group, while 13 cases $(86.7 \%)$ were discharged in 2 nd post-operative day in ICK group, which is statistically insignificant. 
Patient was discharged when he was vitally stable, on full oral feeding, no signs of early postoperative complications. All of the 30 patients in this study were followed-up weekly in the first month.

Table (1): The age characteristics of our study groups.

\begin{tabular}{ccccc}
\hline & Range & Mean \pm SD & $t$-test & $p$-value \\
\hline Age: & & & & \\
GI & $20-35$ & $29.00 \pm 5.10$ & 0.030 & 0.863 \\
GII & $23-39$ & $29.33 \pm 5.39$ & & \\
\hline
\end{tabular}

$t$ : Independent sample $t$-test.

Table (2): The mean operative time among our study groups.

\begin{tabular}{lrrrr}
\hline & Range & Mean \pm SD & $t$-test & $p$-value \\
\hline Operative time: & & & & \\
GI & $30-66$ & $46.07 \pm 11.70$ & 13.886 & $0.001^{*}$ \\
GII & $35-75$ & $61.73 \pm 11.33$ & & \\
\hline
\end{tabular}

$t_{*}:$ Independent sample $t$-test.

: Statistically significant difference.

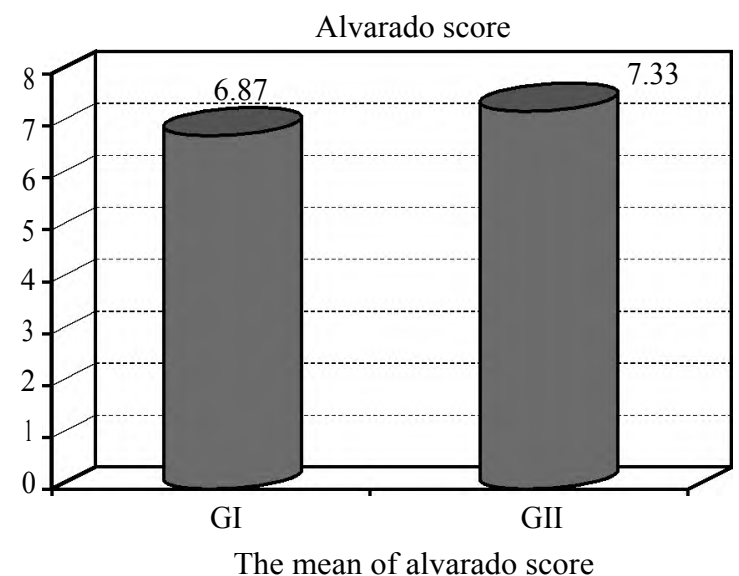

Fig. (3): Alvarado score characteristics of the study groups.

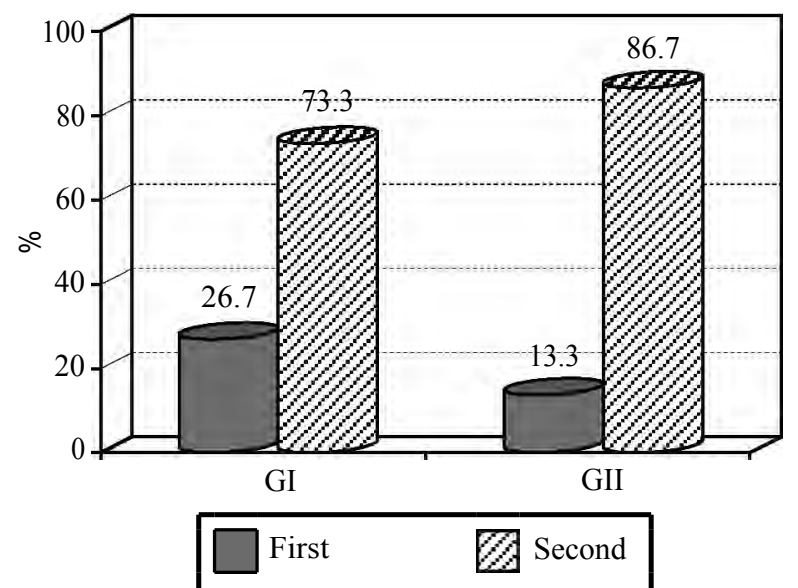

Fig. (4): The hospital stay among both groups.

\section{Discussion}

Appendicular stump closure is a crucial step during laparoscopic appendectomy, and its inappropriate management can lead to catastrophic complications. Different techniques have been described to secure the appendicular base during LA, and despite many studies, there is no universal agreement on any method [9]. There are prospective randomized studies with large number of cases that compared different methods, staplers can be considered when the appendix base is extremely inflamed or necrotic but unfortunately staplers and endoloops are more expensive methods as compared to others. Using cheaper alternatives such as ligation with sutures and handmade loops will be more appropriate due to the particular conditions of poor countries. All methods have a similar reliability, therefore methods that are cheap and easy to apply should be considered as first choice. Nevertheless, the final decision on the method to be used will rely on the surgeon's training and experience, the availability of equipments, costs and the extent of appendix inflammation [3]

Inherent disadvantages of laparoscopic intracorporeal knot tying are; limited space for movement, decreased sensation of the applied tension to the tissues and the knot with difficulty in creating the knot because of technical requirements. In contrast, extracorporeal knots are easier to create, and the surgeon who advances the knot controls the tension. The majority of extracorporeal knots are sliding knots, and this raises concerns about the safety of the ligatures. Due to numerous difficulties and challenges to intracorporeal knot tying, the surgeons try to avoid intracorporeal suturing and make use of extracorporeal technique $[4,10]$.

In our study we compare securing the base of the appendix using extracorporeal sliding-knot versus intracorporeal knot as regard: (Simplicity, operative time, effectiveness and complications).

The presenting age of patients participating in ECK technique was $29.00 \pm 5.10$ years, while in ICK technique the mean age was $29.33 \pm 5.39$ years, with no statistically significant difference.

Our result is similar to Chand Prem et al., [11], who reported in their study comparing ICK with endoloop that the mean age of all patients was 29.01 years, and they explained the cause of high incidence of appendicitis in the second and third decade of life is considerably due to hyperplasia of lymphoid tissue in the appendix, which reaches its peak at 20 years of age. Nadeem et al., [12] reported in their study comparing ECK (36 patients) 
with metallic endoclip ( 32 patients), that the mean age of ECK group was $24 \pm 7.78$ years.

The ECK group in this study showed 9 males $(60 \%)$ and 6 females $(40 \%)$, while ICK group were consisted of 7 males $(46.7 \%)$ and 8 females $(53.3 \%)$, with no statistically significant difference. Ates et al., [13] reported in their study comparing ICK with titanium endoclip that ICK group (31 patients) consisted of 19 males $(61.3 \%)$ and 12 females $(38.7 \%)$. Arcovedo et al., [14] reported in their study comparing Gea extracorporeal slidingknot with stapler that there were 34 male patients $(54 \%)$ and 29 female patients $(46 \%)$ in ECK group.

The operative time in this study showed a statistically highly significant difference between both groups with $p$-value $=0.001$. ECK group had a shorter operative time than ICK group. Interestingly, ICK group in which suture knot was used, had significantly longer duration compared with the ECK group, which can be attributed to the fact that this method seems to be more technically demanding that improve with more training.

The operative time in our study is similar to Nguyen et al., [15] that evaluated two different types of knot-tying techniques-intracorporeal versus extracorporeal-they found in their study a statistically significant difference between the two methods with a performance time for the extracorporeal knot tying technique less than that for the intracorporeal technique with $p$-value $>0.05$.

Elshoura et al., [16] reported in their study comparing endoscopic stapler, ECK and ICK, that the mean operative time of ECK group was 71.5 minutes (range: 40-90 minutes), and of ICK group was 84.3 minutes (range: $45-125$ minutes), while the mean operation time was 56.4 minutes in endostapler group.

They used the post-hoc test that showed statistically significant differences as regards operation time between the groups: Between endostapler group and ECK group the $p$-value was 0.01 ; between endostapler group and ICK group the $p$ value was 0.02; and between ECK group and ICK group the $p$-value was 0.004 [16]

Gonenc et al., [17] reported in their study comparing ICK versus metal endoclip that the mean operative time of ICK group (46 patients) was 61.9 minutes, also Kieudelis et al., [18] found in their study comparing ICK with invaginating suture versus endoloops that the mean operative time of intracorporeal group (40 patients) was $79.6 \pm 21$ minutes. Time was significantly longer because invaginating suture was also used in the study. Nadeem et al., [12], reported in their study comparing ECK (36 patients) with metallic endoclip that the mean operative time of EC knot group was $48.3 \pm 8.45$ minutes.

In ECK group; we inserted a tube drain in 4 patients $(26.7 \%)$. While in ICK group we inserted a tube drain in 2 patients $(13.3 \%)$, with $p$-value $=$ 0.361 , which statistically insignificant. All drains were removed in the second day post-operative.

No cases of mortality or intraoperative complications were reported in our study, although an array of factors were standing behind laparotomy, which had variable frequency, like adhesions, localized perforation, diffuse peritonitis, appendix base necrosis, bleeding, and iatrogenic lesions. Among the 30 studied patients, no patients needed laparotomy.

Kieudelis et al., [18] reported in their study comparing ICK with invaginating suture versus endoloops that one patient of ICK group (40 patients) has intraoperative bleeding. Nadeem et al., [12] reported in their study comparing ECK (36 patients) with metallic endoclip that one patient has intraoperative bleeding in EC knot group.

In this study the intestinal peristalsis returned in ECK group after 14.40 \pm 4.97 hours postoperatively and in ICK group after 17.60 \pm 6.20 hours, with $p$-value $=0.130$ which is statistically insignificant. Chand Prem, et al., [11], reported in their study on 60 patients that the bowel sounds in patients of ICK group (30 patients) returned after $18.80 \pm 8.14$ hours.

There was a post-operative wound infection in one patient $(6.7 \%)$ in ECK group, while two patients $(13.3 \%)$ in ICK group developed wound infection; also each group has one patient (6.7\%) who developed post-operative delayed peristalsis, and regarding intraabdominal abscess there was one patient only in ICK group that has postoperative abscess in the right iliac fossa. No significant statistical difference between two groups as regards post-operative complications.

The three patients who developed superficial wound infection were managed with regular wound care and antibiotics. Two patients experienced delayed peristalsis, which resolved under conservative treatment (nasogastric tube, nothing per month, intravenous fluids, and bowel stimulants). One patient who developed intraabdominal abscess was treated by the placement of ultrasound-guided 
percutaneous tube drain into the abscess under the cover of parental antibiotic regimen.

Elshoura et al., [16] reported in their study that; in ECK group the complication rate was $6.6 \%$ (three cases: One intra-abdominal abscess, one superficial wound infection, and one delayed peristalsis), while in ICK group the complication rate was $2.3 \%$; (one relaparoscopy because of intraabdominal abscess). And in endostapler group the complication rate was $4.2 \%$; (two cases: One superficial wound infection and one intraabdominal abscess).

Chand Prem et al., [11], reported in their study on 60 patients that only one patient in ICK group (30 patients) had wound infection, and none of patients in ICK group had bleeding from the port or the stump. No patient developed delayed peristalsis or intestinal obstruction in the given period of follow-up. No patient had port site hernia in 3 months follow-up period. Nurettin et al., [19], found in their study comparing ICK in complicated and noncomplicated appendicitis on 90 patients that incision site infection was observed in seven cases $(7.8 \%)$, and delayed peristalsis was observed in two cases with complicated appendix (2.2\%).

Nadeem et al., [12] , reported in their study comparing EC sliding knot (36 patients) with metallic endoclip that one patient in EC knot group has post-operative delayed peristalsis, also no postoperative delayed peristalsis has been reported after extracorporeal knotting in studies done by Di Saverio et al., and Arcovedo et al., [14,20]

In this study, 4 cases $(26.7 \%)$ in ECK group were discharged in 1 st post-operative day in comparison to 2 cases $(13.3 \%)$ in ICK group, while in the 2 nd post-operative day; 11 cases $(73.3 \%)$ in ECK group were discharged in comparison to 13 cases $(86.7 \%)$ in ICK group, with no statistically significant difference between the two groups.

The average length of hospitalization in recent studies was from 2 to 5.9 days, showing no statistically significant difference among the various approaches of appendix stump closure $[\mathbf{2 , 2 1}]$. Chand

Prem et al., [11] found in their study on 60 patients that most of patient in ICK group (30 patients) were discharged in 1 st and 2 nd day postoperative except one case was discharged in $3 \mathrm{rd}$ day, due to post-operative pyrexia as a result of port site infection. Ates et al., [13], found in their study comparing IC knot with titanium endoclip that the mean of hospital stay in ICK group (31 patients) was 2.06 \pm 0.9 days. Nadeem et al., [12], reported in their study, that the mean hospital stay among patients in EC knot group was 21.6 \pm 13.6 hours, also the average hospital stay in ECK group reported by Arcovedo et al., [14] was 2.78 days (range, $7 \mathrm{~h}$ to 15 days).

We realize that ligation of the appendicular base should be only moderately tight. The degree of tension applied to the knot is very important as loose knot may cause bleeding or post-operative leakage and collection, also tight closure of the applied knot resulting in cutting or tearing of the tissues, which necessitates conversion to open surgery with transfixing the appendicular stump [22]. In our study we concluded that tension applied to the knot could be controlled through the ECK technique more than the ICK, but we had no case of bleeding or leakage among both group.

\section{Conclusions:}

Application of the ICK and ECK is safe, sure and reliable method for stump closure and enhances the surgical hand skills. Suture ligation is economically cheaper when compared to standard techniques as staplers or endoloops. Finally we can conclude that ECK is safe, easy to learn and carry the advantage of shorter operative time compared to the ICK technique, but we recommend that every laparoscopic surgeon must be acquainted by both techniques.

\section{References}

1- BOBRZYNSKI A., BUDZYNSKI A. and STRZALKA M.: Laparoscopy in abdominal emergencies. Przegl. Lek., 59 (10): 873-6, 2002

2- STRZALKA M., MATYJA M. and REMBIASZ K.: Comparison of the results of laparoscopic appendectomies with application of different techniques for closure of the appendicular stump. World J. Emerg. Surg., 11: 4, 2016.

3- MAYIR B., ENSARI C.O., BILECIK T., et al.: Methods for closure of appendix stump during laparoscopic appendectomy procedure. Ulus. Cerrahi. Derg., 31 (4): 229-31, 2015.

4- MURAD F., ALI Q., MASIHA S.A., et al.: Roeder's knot: Solution to intra-corporeal knot tying. J. Rawalpindi. Med. Coll. (J.R.M.C.), 17: 181-4, 2013.

5- AKINDELE R.A., FASANU A., MONDAL S., et al.: Comparing Extracorporeal Knots in Laparoscopy using Knot and Loop Securities. World Journal of Laparoscopic Surgery, 7 (1): 28-32, 2014.

6- BARBER F.A., HERBERT M.A. and BEAVIS R.C.: Cyclic load and failure behavior of arthroscopic knots and high strength sutures. Arthroscopy: The Journal of Arthroscopic \& Related Surgery, 25 (2): 192-9, 2009.

7- A DOWAIS H.S.: Tying laparoscopic intracorporeal knots with one instrument: "Dowais tie". The Internet Journal of Surgery, Volume 21 Number 2, 2008. 
8- ISMAIL M. and SHALABY R.: Single instrument intracorporeal knot tying during single port laparoscopic hernia repair in children: A new simplified technique. Journal of Pediatric Surgery, 49 (6): 1044-8, 2014.

9- SHAIKH F.M., BAJWA R. and McDONNELL C.O.: Management of appendiceal stump in laparoscopic appendectomy--clips or ligature: A systematic review and metaanalysis. J. Laparoendosc. Adv. Surg. Tech. A., 25 (1): 21-7, 2015.

10- PATTAS M., THEODOROU D., LAGOUDIANAKIS E., et al.: Easyloop knot: A simple and safe extracorporeal knot. The American Journal of Surgery, 191 (6): 821-2, 2006.

11-CHAND P., SINGH G., KAHLON P.S., et al.: Comparison of Stump Closure Techniques of The Base of The Appendix In Laparoscopic Appendectomy. Journal of Evolution of Medical And Dental Sciences-JEMDS, 6 (72): 5092-7, 2017.

12- NADEEM M., KHAN S., ALI S., et al.: Comparison of extra-corporeal knot-tying suture and metallic endo-clips in laparoscopic appendiceal stump closure in uncomplicated acute appendicitis. International Journal of Surgery Open, 2: 11-4, 2016

13- ATES M., DIRICAN A., INCE V., et al.: Comparison of intracorporeal knot-tying suture (polyglactin) and titanium endoclips in laparoscopic appendiceal stump closure: A prospective randomized study. Surgical Laparoscopy Endoscopy \& Percutaneous Techniques, 22 (3): 226-31, 2012.

14- ARCOVEDO R., BARRERA H. and REYES H.S.: Securing the appendiceal stump with the Gea extracorporeal sliding knot during laparoscopic appendectomy is safe and economical. Surg. Endosc., 21 (10): 1764-7, 2007.

15- NGUYEN N.T., MAYER K.L., BOLD R.J., et al.: Lapar- oscopic suturing evaluation among surgical residents. The Journal of Surgical Research, 93 (1): 133-6, 2000.

16-ELSHOURA A., HASSAN O. and SABER S.: Application of different methods for stump closure in laparoscopic appendectomy. The Egyptian Journal of Surgery, 36 (2): 131, 2017.

17- GONENC M., GEMICI E., KALAYCI M.U., et al.: Intracorporeal knotting versus metal endoclip application for the closure of the appendiceal stump during laparoscopic appendectomy in uncomplicated appendicitis. J. Laparoendosc. Adv. Surg. Tech. A., 22, 2012.

18- KIUDELIS M., IGNATAVICIUS P., ZVINIENE K., et al.: Analysis of intracorporeal knotting with invaginating suture versus endoloops in appendiceal stump closure. Wideochir Inne Tech. Maloinwazyjne, 8 (1): 69-73, 2013.

19- AY N., DINC B., ALP V., et al.: Comparison of outcomes of laparoscopic intracorporeal knotting technique in patients with complicated and noncomplicated acute appendicitis. Ther. Clin. Risk Manag., 11: 1213-6, 2015.

20- Di SAVERIO S., MANDRIOLI M., SIBILIO A., et al.: A cost-effective technique for laparoscopic appendectomy: Outcomes and costs of a case-control prospective singleoperator study of 112 unselected consecutive cases of complicated acute appendicitis. Journal of the American College of Surgeons, 218 (3): e51-e65, 2014.

21- SWANK H.A., VAN ROSSEM C.C., VAN GELOVEN A.A., et al.: Endostapler or endoloops or securing the appendiceal stump in laparoscopic appendectomy: A retrospective cohort study. Surgical endoscopy, 28 (2): 576-83, 2014

22- CHIKAMORI F., KUNIYOSHI N., SHIBUYA S., et al.: Appendiceal stump abscess as an early complication of laparoscopic appendectomy: Report of a case. Surgery today, 32 (10): 919-21, 2002. 


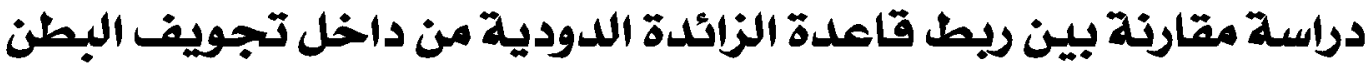

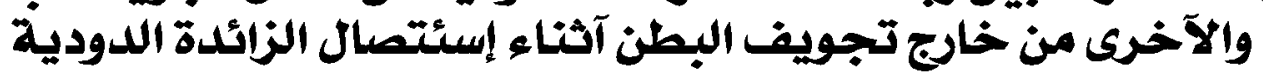 بالمنظار الجراحى آداء إسئح}

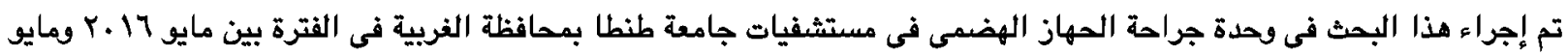

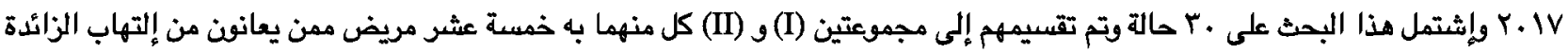

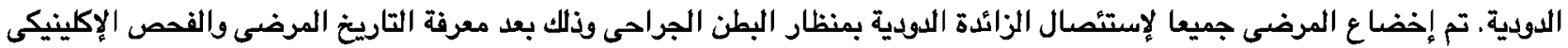

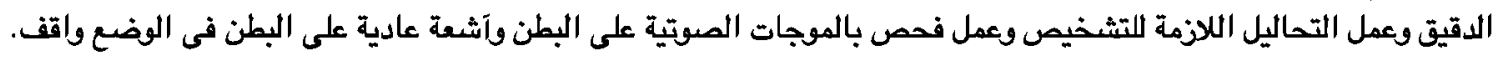

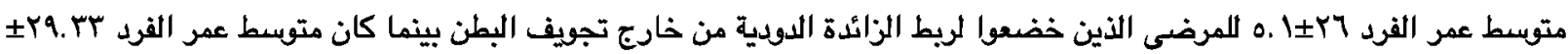

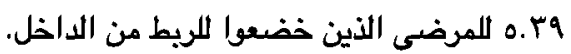

$$
\text { شملت الدراسة } 17 \text { مريض ذكرا وعا مريضة آثثى. }
$$

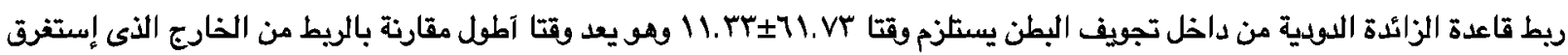

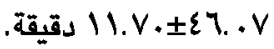

لا يوجد فرق بين كلا الطريقتين من حيث: الآلم بعد العملية، حدوث تآخر بحركة الآمعاء. إشتكى مريضان من إلتهاب سطحى بالجرح بعد إجراء الجراحة عن طريق الربط من داخل تجويف البطن بينما إشتكى مريض واحد من

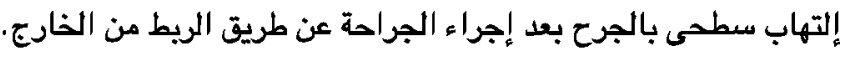

إشتكى مريض واحد فقط من تجمع صديدى بعد الجراحة فى الجزء الآيمن من آسفل البطن بعد الربط من داخل تجويف البطن.

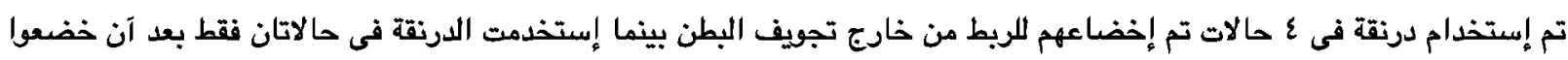

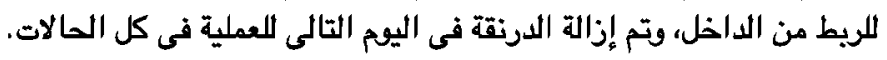

$$
\text { المستخلص من البحث: لم يتم مقابلة آى مضاعفات آثناء الجراحة من نزيف حاد آو اللجوء إلى الفتح الجراحى. }
$$

• لإستئصال الزائدة الدودية بمنظار البطن الجراحى قيمة تشخيصية وعلاجية للآمراض المصاحبة لإلتهاب الزائدة الدودية خاصة فى النساء. • لا يوجد إتفاق على طريقة واحدة تكون الآفضل لريط قاعدة الزائدة الدودية ولكن ربطها عن طريق إستخدام العقد من داخل آو خارج تجويف البطن يعتبر آمن وآقل تكلفة من الطرق الآخرى.

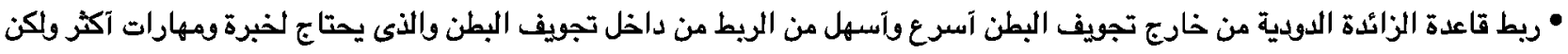

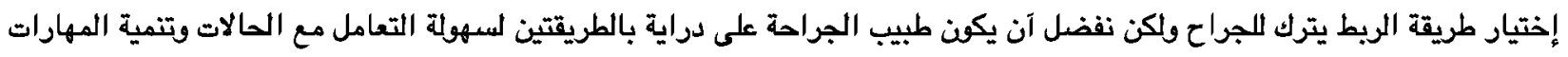

